\title{
CORPO E LINGUAGEM: PERSPECTIVAS DISCURSIVAS E INTERDISCIPLINARES
}

\author{
ELISANDRA FiLETti ${ }^{*}$ \\ Régis Henrique dos Reis Silva*
}

\begin{abstract}
Resumo
O presente artigo refere-se a um processo de elaboração e desenvolvimento da disciplina "Corpo e Linguagem”, ofertada aos estudantes do Ensino Médio do Cepae/UFG. É um trabalho de natureza interdisciplinar, originado a partir do objetivo de se estabelecer uma correlação entre a linguagem corporal, aqui entendida como um discurso de natureza não-verbal, com a linguagem verbal. O modo como o Corpo é tratado, sendo este Linguagem, suscitou uma série de questóes como a compreensão das perspectivas históricas sobre o corpo, a publicidade do corpo na atualidade, relaçóes de poder, entre outras. A importância dessa reflexão sobre Corpo e Linguagem nos permitiu estabelecer um diálogo profícuo acerca da dicotomia Mente $x$ Corpo, bem como entender as decorrências sócio-culturais dessa cisão nas práticas discursivas que envolvem o homem moderno. A importância dessa relaçáo sobre corpo e linguagem possibilitou uma oportunidade a esses estudantes de terem acesso a temas polêmicos e, a partir deles, estabelecer outros pontos de vista acerca da inserção do homem na prática discursiva.
\end{abstract}

PalaVras-ChaVE: corpo, linguagem, discurso, práticas discursivas, práticas sociais.

\section{Body and Language: discursive and interdisciplinary perspectives}

\section{Abstract}

This paper is about a process of elaboration and development of the subject "Body and Language", offered to High School students in Cepae. It is an interdisciplinary work which originated from the aim at establishing a correlation between corporal language, understood here as a non-verbal language, and the verbal language. The way the body is treated as language elicited a number of questions such as the understanding of historical perspectives about the body, the current advertising of the body, power relations, among others. The work developed in this subject allowed us to establish a proficuous dialogue on the mind-body dichotomy as well as to understand the sociocultural consequences of this split. The importance of this reflection upon the body and language gave the opportunity to the students to have access to polemic themes which allowed them to establish other points of view about the insertion of man in the discursive practice.

KEY WORDs: body, language, discourse, discursive practices, social practices.

* Professora de Língua Portuguesa do Centro de Ensino e Pesquisa Aplicada à Educação (Cepae/UFG). Email: elisandra.filetti@uol.com.br.

** Professor de Educação Física, Centro de Ensino e Pesquisa Aplicada à Educação (Cepae/ UFG).Email: regishsilva@universia.com.br. 


\section{Revista Solta a Voz, v. 19, n. 2}

\section{INTRODUÇÃo}

Este trabalho originou-se da elaboração e desenvolvimento de uma disciplina, de caráter interdisciplinar, ofertada como disciplina acessória do Ensino Médio (EM) e desenvolvida no Centro de Ensino e Pesquisa Aplicada a Educação da Universidade Federal de Goiás (Cepae/UFG) ${ }^{1}$.

Para tanto, discutiremos, inicialmente, de forma sucinta, o processo de inserção do Cepae como unidade acadêmica especial da UFG. Em seguida, apresentaremos como se deu o processo de elaboração da disciplina intitulada "Corpo e Linguagem", com destaque para a Reforma Curricular do Ensino Médio no Cepae/UFG. Na seqüência, ainda, apresentaremos a fundamentação teórica da disciplina e as estratégias de ensino desenvolvidas junto aos alunos. Por fim, apresentaremos nossas conclusóes acerca desse trabalho.

O Cepae/UFG possui corpo docente formado por professores doutores, mestres e pesquisadores envolvidos com o ensino nos níveis Fundamental, Médio e Superior. Em linhas gerais, essa instituição apresenta propostas que pretendem inovar o currículo escolar e destina-se a educar alunos da Educação Básica, bem como procura contribuir efetivamente para o processo de formação de futuros professores, desenvolvendo também pesquisas científicas, implementando práticas pedagógicas, além de avaliar novos currículos, de maneira a trabalhar com docentes na perspectiva da formação continuada.

O Colégio de Aplicação foi criado pelo Decreto Lei no 9053, de 12/03/1966, e suas atividades iniciaram em março de 1968, no prédio da Faculdade de Educação da UFG (FE/UFG). No plano da Reforma Universitária, ocorrida em 1968, o Colégio de Aplicação foi agregado a FE/ UFG, constituindo-se assim como órgão suplementar daquela unidade (Cepae/UFG, 2006).

No início de suas atividades, o Colégio de Aplicação, além de constituir-se como escola experimental para novos cursos previstos na legislação vigente, passou a servir como Campo de Estágio Supervisionado para as Licenciaturas e para as habilitaçóes do curso de Pedagogia. O corpo

1 Essa disciplina, assim como outras, constitui um leque de disciplinas acessórias direcionadas a alunos que optam pela Área de Humanas, o que permite que esse aluno integralize seu currículo de Ensino Médio no Cepae/UFG (Cf. Delgado et al., 2007). 
docente do então Colégio de Aplicação da FE/UFG era constituído por Professores da Carreira de $1^{\circ}$ e $2^{\circ}$ graus, juntamente com professores da Faculdade de Educação que também atuavam neste nível de ensino.

A partir de 1980, resultado de uma reivindicação de greve, os professores de $1^{\circ}$ e $2^{\circ}$ graus foram reclassificados na Carreira do Magistério Superior, por já estarem desempenhando esta função, semelhantemente aos demais professores da UFG (Cepae/UFG, 2006). Posteriormente, em 1982, foi criado o Departamento de Estudos Aplicados à Educação da FE/ UFG, composto pelos membros do Colégio de Aplicação, que funcionaria até março de 1994, quando foi então criado o Cepae/UFG, por meio da portaria $n^{\circ} 0063$, do Magnífico Reitor, tendo o Cepae como finalidade a realização do Ensino, da Pesquisa e da Extensão, instrumentos de participação na formação de novos educadores, nas diversas áreas do conhecimento, além de ter também como finalidade atender aos diversos cursos de Licenciatura da UFG (Cepae/UFG, 2006).

A idéia de criaçáo do Cepae resultou de intensas discussóes no interior dessa Universidade, especificamente nos Seminários de Licenciatura e em debates e estudos que visavam à formação de uma política acadêmica para as Licenciaturas, em especial, no Fórum de Licenciatura, instituído em 1992. A definição dessa política foi avançando em suas metas e propostas e à medida que os projetos foram sendo pensados, construídos e fortificados pôde-se testemunhar a consolidação do papel fundamental do Cepae no processo de reflexão, reformulação e fortalecimento das Licenciaturas da UFG (Cepae/UFG, 2006). Todo esse histórico demonstra a trajetória do Cepae em busca de sua identidade como um dos poucos centros de ensino que se dedica à pesquisa voltada ao Ensino Básico no Brasil.

\section{O Cepae e a Reforma Curricular do Ensino Médio}

Atualmente, a organização pedagógica do Cepae/UFG passa a se configurar em Áreas e Subáreas de Conhecimento, quais sejam: Área de Ciências da Natureza e Matemática, Área de Ciências Humanas e Filosofia, Área de Comunicação (da qual fazem parte, dentre outras, as subáreas de Educação Física e Língua Portuguesa). Assim, o Cepae vem, ao longo dos anos, constituindo-se como campo de Ensino, Estágio, Pesquisa e Extensão da UFG, em que têm surgido trabalhos que refletem as relaçôes de 


\section{Revista Solta a Voz, v. 19, n. 2}

ensino-aprendizagem mediadas por todas essas instâncias, o que tem caracterizado um trabalho de se repensar constantemente a prática educativa. Fruto dessas reflexóes foi a Reforma Curricular do Ensino Médio (Delgado et al., 2007), que tem remodelado a estrutura pedagógica do Cepae não somente em relação ao EM, como em relação às propostas pedagógicas criadas para atender a novas perspectivas.

A nova estrutura curricular do Ensino Médio foi organizada em dois turnos: no matutino funciona o Núcleo Básico, composto por Disciplinas Obrigatórias comuns a qualquer currículo escolar, e, no turno vespertino, os alunos cursam o Núcleo Flexivel do currículo, constituído de Disciplinas Acessório-Obrigatórias e Optativas. No primeiro ano do EM, os alunos optam por uma das Áreas de Conhecimento - Biológicas, Exatas ou Humanas - e, entre as disciplinas ofertadas por essas áreas de conhecimento, fazem opção por aquelas que melhor se adéqüem à integralização de seu currículo.

A Reforma implantada teve como princípios fundamentais a construção da autonomia por parte dos alunos, o que é desenvolvido mediante sua escolha em relação à área de conhecimento com a qual se identifica e também por meio de trabalhos interdisciplinares, construídos pelo corpo docente do Cepae.

No seio das discussóes acerca das contribuiçóes que a interdisciplinaridade pode dar ao processo de ensino-aprendizagem surgiu a disciplina Corpo e Linguagem. Sendo assim, a proposta interdisciplinar desse curso se pautou no seguinte conceito de interdisciplinaridade: Pesquisa da realidade, em todas as suas relaçóes e interconexóes - por meio de um método integral de apreensão da realidade (Materialismo Histórico Dialético). Por isso, não pode ser confundida com multidisciplinaridade, que consiste na justaposição do conhecimento produzido anteriormente de forma isolada, o qual reúne um conjunto de especialistas que detém, cada um deles, seu conhecimento (Freitas, 1995). Portanto, o que a interdisciplinaridade pretende realizar é um estudo conjunto, entre as diferentes áreas do conhecimento, a partir do qual o "novo" conhecimento produzido é integrado e não justaposto mecanicamente depois de gerado fragmentariamente (Kopnin, 1978).

Nesse sentido, o trabalho interdisciplinar de Corpo e Linguagem se orientou pela perspectiva de Kopnin (1978) e de Freitas (1995), tendo como proposta refletir sobre o papel da Linguagem na compreensão do 
Corpo e como este, juntamente com a Linguagem, contribui para constituição identitária de um indivíduo. Para isso, a disciplina foi idealizada durante todo o primeiro semestre de 2007, sendo que nós, professores de Língua Portuguesa e Educação Física, nos encontrávamos periodicamente para selecionar e discutirmos os textos teóricos que dariam suporte às nossas aulas, bem como a seleção e montagem dos textos e atividades que seriam utilizados pelos alunos.

É importante ressaltar que essa disciplina não se tornou uma extensão de uma disciplina da área de Língua Portuguesa ou da área de Educação Física. De fato, Corpo e Linguagem assumiu um caráter interdisciplinar, pois, mesmo que a fundamentação teórica inicial viesse de referências diversas, como teorias acerca da expressão lingüística, do pensamento social e de uma reflexão a respeito do corpo por parte da Educação Física, a disciplina configurou-se por uma identidade própria, interdisciplinar, em virtude da maneira como fomos problematizando o objeto em estudo. Neste sentido, dialogamos não somente com áreas diretamente ligadas ao curso de formação dos professores responsáveis pela disciplina, como a Lingüística e a Educação Física, mas com outras áreas do conhecimento como a História da Arte, a Política, a Filosofia, embora não houvesse a presença de professores dessas áreas de conhecimento.

A intenção de oferecer um ensino sustentado por uma idéia de formação universal do Homem parece ter sido o ponto-chave para oferecer aos alunos do Cepae uma educação que se deseja mais ampla, que valoriza o conhecimento de várias áreas e que pretende estabelecer um diálogo profícuo entre conhecimentos. Nesse sentido, a disciplina Corpo e Linguagem caracterizou-se por abordar temas como a importância da linguagem e do corpo na comunicação humana; o corpo como uma manifestação de linguagem; concepçôes de corpo ao longo da História, suas representaçôes; corpo e poder; além de refletir sobre o papel que o homem moderno, como sujeito de um saber sócio-histórico, especialmente em fins do século passado e início do século XXI, tem assumido.

Para entender esse processo sócio-histórico e discursivo, é importante perceber que, em uma época em que as práticas de linguagem passam pela evidência de um padrão corporal socialmente aceito, bem como pelas relaçôes de poder (Foucault, 1979) subjacentes a essas práticas, o sujeito 


\section{Revista Solta a Voz, v. 19, n. 2}

atento a esse processo torna-se melhor preparado para a vida. Seguindo essa abordagem, Porter (1992, p. 292) afirma que

Até há pouco tempo, a história do corpo tem sido, em geral, negligenciada, não sendo difícil se perceber porquê. Por um lado, os componentes clássicos, e por outro, os judaico-cristãos, de nossa herança cultural, avançaram ambos para uma visão fundamentalmente dualista de homem, entendida como uma aliança muitas vezes ansiosa da mente e do corpo, da psique e do soma; e, ambas as tradiçóes, em seus caminhos diferentes e por razóes diferentes, elevaram a mente ou a alma e denegriram o corpo.

E foi isso que a disciplina Corpo e Linguagem buscou suscitar: discussão e reflexão, por parte do público jovem do Ensino Médio, no que se refere a certos ícones que são veiculados nos meios de comunicação, impressos e digitais, e que tem sido "consumidos" pelas novas geraçóes, muitas vezes sem refletir acerca de sua influência sobre o comportamento humano no que tange à dissociação da mente do corpo.

\section{Construindo A DISCIPLINA}

A justificativa deste trabalho, num primeiro momento, se dá por acreditarmos nos princípios que têm norteado o trabalho dos professores das subáreas de Educação Física e Língua Portuguesa e, num segundo momento, por acreditarmos que "executa quem planeja" (ver Muñoz Palafox, 2001). Dito de outra forma, o professor deve ser responsável pela pesquisa de sua própria práxis pedagógica e, assim sendo, deve aproveitar os diversos espaços de divulgação acadêmico-científica para expor à comunidade sua práxis, cujo intuito é socializar experiências com os demais companheiros de profissão, constatando os limites e as possibilidades do exercício profissional nesta primeira década do século XXI.

As estratégias de ensino da disciplina Corpo e Linguagem foram desenvolvidas à medida que a nova dinâmica do ensino médio ia sendo alterada com a criação de um novo leque de disciplinas e propostas pedagógicas interdisciplinares.

Nesse sentido, apesar da organização pedagógica do Cepae se dar em um regime de seriação, mais precisamente em anos de escolarização, 
as disciplinas do Núcleo Flexivel do currículo seguem uma lógica de ciclos, pois são ofertadas semestralmente a todos os alunos dos três anos do ensino médio.

De acordo com o Coletivo de Autores (1992), os alunos do EM geralmente estão no quarto ciclo de desenvolvimento humano, denominado aprofundamento da sistematização do conhecimento. Neste ciclo, o aluno adquire uma relação especial com o objeto de estudo, que lhe permite refletir sobre ele. O educando começa a perceber, compreender e explicar que há propriedades comuns e regulares nos objetos, no conhecimento.

Dessa forma, no tocante à aprendizagem, o salto qualitativo ocorre quando o aluno estabelece as regularidades dos objetos. É nesse ciclo que o aluno lida com a regularidade científica, podendo, a partir dela, adquirir algumas condições objetivas para ser produtor de conhecimento científico quando submetido à atividade de pesquisa. É, portanto, a ilustração de que os alunos estão prontos a tornarem-se autônomos, críticos, princípio fundamental que está na base de nossa proposta.

\section{OS EIXOS DA DISCIPLINA: LINGUAGEM-CORPO}

Para a sustentação das idéias relativas a um indivíduo autônomo, recorremos ao teórico Bakhtin (1997, 1999), segundo o qual a linguagem é dialógica por excelência e pressupóe sempre a existência do Outro, que se expressa porque há um interlocutor que o estimula e que interfere no conteúdo do que é dito ou não dito. Nessa perspectiva, a língua e a linguagem não são lineares; apresentam-se heterogêneas, funcionais, em sua multiplicidade de sentidos e discursos. E como há uma variedade de pontos de vista, por vezes conflituosos, a linguagem se manifesta polissêmica, constituída na forma de interdiscursos (Cf. Plano de Ensino da Subárea de LP, 2008). Portanto, a concepçâo de autonomia que procuramos difundir está ligada ao exercício do pensamento e da linguagem, indissociados da compreensão de si como corpo físico.

As discussóes travadas durante a elaboração da disciplina Corpo e Linguagem tomam como princípio o conceito de interação, segundo o qual a lingua(gem) é decorrente de um processo sócio-histórico. Para Bakhtin (apud Aranha, 1992, p. 105), linguagem é um 


\section{Revista Solta a Voz, v. 19, n. 2}

[...] elemento constitutivo da prática social material [...] pois é ao mesmo tempo prática material e um processo no qual muitas atividades complexas de tipo menos manifestadamente material - da informação à interação, da representação à imaginação e do pensamento abstrato à emoção imediata - são realizadas especificamente. A linguagem é, de fato, um tipo especial de prática material, a sociabilidade humana [...]. É uma atividade socialmente partilhada e recíproca, já incorporada nas relaçóes ativas, dentro das quais todo movimento é uma ativação do que já é partilhado e recíproco, ou pode vir a sê-lo. (grifo nosso)

Sendo assim, o caráter material da linguagem destaca-se, pois ela é um

[...] campo de conflitos e contradiçóes, corporificação de diferenças e/ou desigualdades. Da família à escola, da igreja ao sindicato, da fábrica ao museu, não importa se são grandes ou pequenos "acontecimentos", o que conta é o fato de, conjuntamente, configurarem uma consciência coletiva. (Bakhtin apud Aranha, 1992, p. 106)

Outra concepção que se alia a de Bakhtin é a de Gramsci (1987, p. 12):

[...] se é verdade que toda linguagem contém elementos de uma concepção de mundo e de uma cultura será igualmente verdade que, a partir da linguagem de cada um, é possível julgar da maior ou menor complexidade da sua concepção do mundo [...] Pela própria concepção do mundo, pertencemos sempre a um determinado grupo, precisamente o de todos os elementos sociais.

Enfim, de acordo com Egan (2002), a linguagem emerge do corpo e, por sua vez, como espécie e indivíduo, teríamos a linguagem corporal surgindo concomitantemente à linguagem verbal. Assim, a linguagem, seja verbal ou não-verbal, é instrumento intelectual que acumulamos à medida que nos desenvolvemos como seres humanos e que serve como mediação do nosso tempo de compreensão e construção da vida e do mundo.

Assim, o falante, ao comunicar-se verbalmente ou não, apresenta-se constituído por um conhecimento enciclopédico, partilhado, representante de uma memória discursiva que vai se estratificando ao longo dos séculos. Nesse sentido, a linguagem vai sendo carregada de conteúdos ou sentidos 
ideológicos. Esses sentidos possíveis são produzidos por posições ideológicas, que constituem a identidade dos indivíduos, manifestadas nas práticas verbais/corporais. Essa identidade só se manifesta por meio da linguagem, em qualquer estado, e dá forma ao comportamento dos indivíduos em sociedade (Pinto, 2004).

Os jogos de linguagem são claramente jogos discursivos de poder, manifestados pela expressão ora explícita do discurso verbal, ora implícita, das imagens metafóricas, simbólicas. Os jogos de linguagem pressupóem as artimanhas de "convencimento do outro, expressando uma 'imposição' direta ou indireta de uma visáo de mundo; conseqüentemente, representam os jogos sociais de poder".

Para Foucault, as relaçóes de poder adquirem nuances diferentes ao longo da História. O corpo, no século XIX, por exemplo, passa a ser visto como um corpo social, uma representação institucional. Assim sendo, a materialidade que esse corpo social exerce, como símbolo do poder, estende todo o seu domínio sobre o indivíduo:

a consciência de seu próprio corpo só pôde ser adquirida pelo efeito do investimento do corpo pelo poder: a ginástica, os exercícios, o desenvolvimento muscular, a nudez, a exaltação do belo corpo... tudo isto conduz ao desejo de seu próprio corpo através de um trabalho insistente, obstinado, meticuloso, que o poder exerceu sobre o corpo das crianças, dos soldados, sobre o corpo sadio. Mas, a partir do momento em que o poder produziu este efeito, como conseqüência direta de suas conquistas, emerge inevitavelmente a reivindicação de seu próprio corpo contra o poder, a saúde contra a economia, o prazer contra as normas morais da sexualidade, do casamento, do pudor. E, assim, o que tornava forte o poder passa a ser aquilo por que ele é atacado... O poder penetrou no corpo, encontra-se exposto no próprio corpo. (Foucault, 1979, p. 82-83)

Nesse sentido, não se pode pensar uma relação entre Corpo/Linguagem sem considerar as condiçóes subjacentes que promovem o exercício dessa linguagem num espaço e tempo delimitado sócio-historicamente, expressando os conflitos inerentes aos jogos de poder.

Pêucheux (1997), outro teórico da Análise do Discurso de linha francesa, argumenta que a luta ao poder e a imposição de um padrão pela classe dominante são decorrentes da objetividade material e ideológica, caracterizada pela estrutura de desigualdade-subordinação do "complexo 
dominante" das formações ideológicas, estrutura que é senão a da contradição reproduçáo/transformação, que constitui a luta ideológica de classes (Pêucheux, 1997, p. 147).

Em muitos momentos, a "imposição" de um padrão comportamental, por exemplo, é reflexo não do curso natural da história de uma sociedade ou de fatos entendidos como arbitrários, mas derivam de um tipo de visão de mundo obviamente "vendida" pelas instâncias que influenciam a formação de opinião, desde o poder público até outros veículos formadores de opinião como a mídia.

Uma concepção ampliada das práticas de linguagem pode ser compreendida como uma teoria do discurso, na medida em que contempla a língua como sistema formal e também como uma manifestação sociocultural, simbólica e histórica. Nessa perspectiva, a substância da língua não é constituída por um sistema abstrato de formas lingüísticas, nem pela enunciação monológica isolada, nem somente pelo ato psicofisiológico de sua produção, mas, sobretudo, pelo fenômeno social da interação verbal, o discurso (Bakhtin, 1997).

A natureza sígnica da língua/linguagem se traduz numa relação entre os elementos lingüísticos de base e a forma que adquirem no contexto discursivo. Pêucheux (1997, p. 222) estabelece um questionamento interessante a esse respeito:

O que dizer, senão que o funcionamento dos elementos lógico-lingüísticos de um enunciado depende das formaçóes discursivas no interior das quais cada um desses elementos pode tomar um "sentido", de modo que, em última instância, será a configuração das formaçôes discursivas no interior das quais se inscreve uma subjetividade dada que determinará $o$ "sentido" que esse enunciado tomará como caráter necessário ou contingente, disjunto ou integrado, etc., dos objetos e propriedades que nele se manifestam?

O que une trabalhos de autores como Bakhtin e Pêucheux, de acordo com a perspectiva que adotamos neste artigo, é o fato desses autores considerarem as práticas de linguagem envoltas por um discurso historicamente constituído. Essa prática discursiva é estabelecida por um movimento contínuo, em que o sujeito constrói sua identidade a partir da memória discursiva, política e histórica, ao mesmo tempo em que a configura socialmente. 


\section{PrátICAS CORPORAIS COMO PRÁTICAS DISCURSIVAS}

Entendemos que alguns conceitos são extremamente relevantes para o desenvolvimento deste artigo, tais como corpo e discurso corporal. Corpo é aqui entendido como uma representação universal de Homem, isto é, corpo e mente; são instâncias complementares daquilo que constitui a humanidade. Assim, não se pode separar corpo e mente, pois são as duas manifestaçóes de um todo, que é o Homem, e este é formado por todas as experiências ontológicas que lhe permitem ser o que é na contemporaneidade.

Sendo o Corpo não destituído da Mente, sua manifestação do Ser, em sociedade, só é possível por meio da linguagem, do discurso. Nesse sentido, o discurso corporal nada mais revela que uma das facetas plurais da complexidade que é a linguagem humana, e, nessa complexidade, esvai-se a idéia de que corpo é apenas uma manifestação de sistemas biológicos e fisiológicos, enquanto a mente representa um sistema de funçóes superiores que comanda o corpo.

Nossa perspectiva propóe trazer à tona a idéia de que Corpo e Mente não são elementos dissociados, mas integram o homem como um todo e o constituem juntamente com os contextos históricos, políticos e culturais que formam esse homem em sua totalidade. Sendo o homem um ser social, assim constitui-se porque a linguagem o permite e é a partir de discussóes acerca da natureza dessa linguagem que nossa disciplina ganhou forma.

Considerando a importância de se relacionar as práticas discursivas à expressão corporal é que Corpo e Linguagem estabeleceu, inicialmente, uma reflexão acerca da função da linguagem e do corpo como manifestaçâo da linguagem não-verbal. Para isso, tomamos como ponto de partida a seguinte questão: Podemos falar em Discurso Corporal? Se sim, podemos dizer que a linguagem não-verbal também é uma característica fundante do "Discurso Corporal". Assim sendo, o Discurso Corporal, da mesma maneira que o Discurso Artístico (ponto de partida para o estabelecimento de uma tipologia, uma vez que trabalha a expressão não-verbal), apresenta como algumas de suas características a polissemia e a paráfrase (Neckel, 2006, p. 6).

A aquisição de conhecimentos a respeito da linguagem não-verbal, bem como a habilidade de enviar ou receber sinais não-verbais, estão es- 


\section{Revista Solta a Voz, v. 19, n. 2}

treitamente relacionadas com a atuação do indivíduo na sociedade (Assis et al., 2005). Pode-se dizer que em qualquer situação comunicativa a presença da linguagem não-verbal é inevitável.

Nessa abordagem, o corpo é tratado como signo lingüístico; apresenta-se como um instrumento de linguagem que evoca o que Bourdieu (1999, 1982) denomina como habitus (Cf. Lopes, 1999) - fenômeno de movimento duplo de interiorização e exteriorização das condiçôes objetivas de existência, que se traduz sob a percepção das coisas, das representaçóes e dos comportamentos sociais, constituídos na primazia da linguagem, da representação da cultura mediada pelo exercício da linguagem (Cf. Filho e Martino, 2003).

Diante dessas consideraçóes e a partir do diagnóstico dos interesses dos nossos alunos, bem como de sua concepção de corpo, manifestada muitas vezes na preocupação com a aparência física, elaboramos a seguinte questão: Temos um corpo ou somos um corpo? Muitos alunos ainda apresentaram uma concepção dicotômica de Corpo e Mente.

Segundo Werneck (2003), os sentidos sociais atribuídos ao corpo, como uma esfera biofísica submetida à racionalidade, são oriundos da dicotomia corpo e mente, desde a Antigüidade Clássica (com os pré-socráticos) e está presente em nossos dias, fazendo com que tudo que esteja relacionado ao corpo ocupe uma posição inferior nas estruturas hierarquizadas. Portanto, a resposta dos nossos alunos é compreensível na medida em que os sentidos sociais atribuídos ao corpo e vivenciados nos ambientes escolares ainda dicotomizam a relação corpo e mente.

Uma das atividades propostas visava estabelecer uma linha temporal que marcasse as concepçóes acerca de Corpo e Linguagem, demonstrando como o Homem foi se constituindo e refletindo sobre os fenômenos que o constituíam.

Inicialmente foi apresentada uma imagem do corpo de um atleta grego (figura 1) e depois a do Homem Vetruviano (figura 2), de Da Vinci, que evidenciam a importância da mente e do corpo como representação da unidade humana. Nessa fase do curso, as discussóes giraram em torno da separação entre atitudes corporais e intelectuais do homem clássico, sobre como os alunos entendiam essa separaçáo, que conseqüências a dualidade corpo $\mathrm{x}$ alma (intelecto) trouxe para a modernidade etc. 


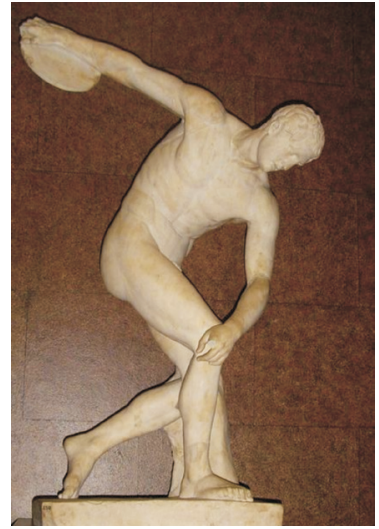

Figura 1 - Discobolus

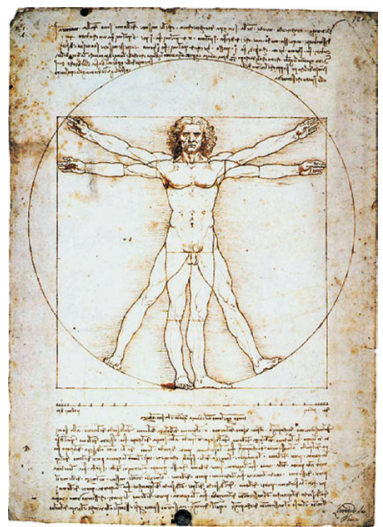

Figura 2 - Homem Vetruviano - Da Vinci

Recorrendo à idéia de que as expressóes corporais demonstram a concepção de Homem da época, trabalhamos alguns exercícios que buscavam comparar e distinguir obras artísticas e a visão de corpo que vigorava quando elas foram produzidas. Essas reflexóes levaram os alunos a perceberem os pontos de vista subjacentes às composiçóes e a ampliar a noção de Belo que possuíam. Vejamos algumas imagens a seguir.

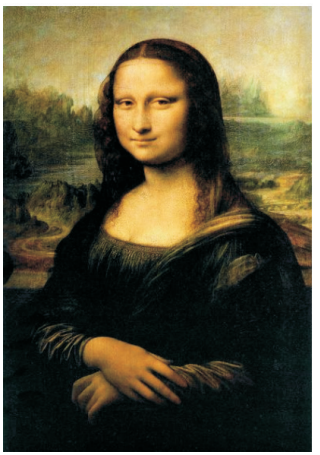

Figura 3 - Mona Lisa Da Vinci (1503-1507)

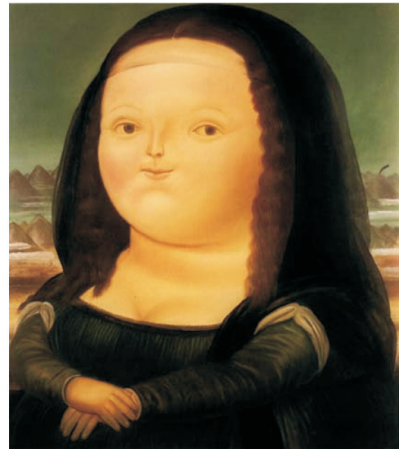

Figura 4 - Mona Lisa - Botero (1932)

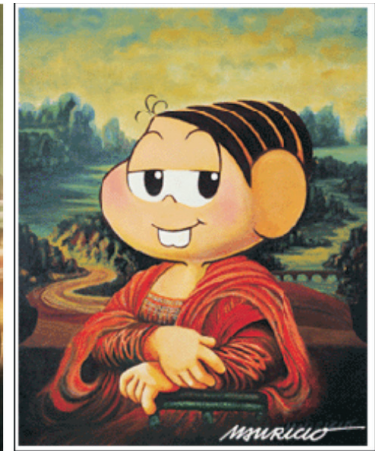

Figura 5 - Mônica Lisa Maurício de Souza (2001)

As três imagens referem-se à La Gioconda ou Mona Lisa (figura 3), mais notável obra do pintor renascentista Leonardo Da Vinci. O sorriso discreto, sedutor, impressiona o espectador e apresenta-lhe o tipo de be- 


\section{Revista Solta a Voz, v. 19, n. 2}

leza característica do século XVI. Tornou-se uma das obras plásticas mais reconhecidas do Ocidente e foi parafraseada por diversos outros artistas, entre eles o pintor colombiano Fernando Botero, que retrata suas obras de maneira rotunda (figura 4), o que estabelece uma crítica quanto à representaçáo do belo pela arte tradicional.

As paráfrases utilizadas pelo autor estabelecem um diálogo com as formas retratadas pela Antigüidade, em que os corpos rechonchudos eram sinais de beleza. Em sua pintura, não se trata de representar indivíduos com sobrepeso, mas uma opção estética de retrato das formas e volumes. Atribuindo esse mesmo tom parafrástico ao retratar a Mônica Lisa (figura 5) em histórias em quadrinho, Maurício de Souza, cartunista brasileiro, expressa a relação entre a arte erudita e a pop art, atribuindo uma pitada de humor e trazendo ao universo infantil, e não somente a ele, a socialização de um conhecimento, antes restrito a poucos, mas agora dirigido a um público maior. Essas correlaçóes foram objeto de discussóes e suscitaram reflexôes bastante interessantes por parte dos alunos, como o fato de alguns temas e algumas técnicas artísticas serem revisitadas, assim como as concepçôes de corpo e linguagem, ao longo do tempo.

Ao criticarmos esta visão dicotomizada e tentarmos superar a compreensão de corpo apenas como esfera biofísica, surgiu outra questão: 0 que é o corpo?

Para respondermos a essa questão nos baseamos no texto de Alves (2004), segundo o qual o conceito de Corpo parte do pressuposto de que somos corpos que fazem parte e transformam a realidade. Corpos vivos em tempo e espaços diferenciados, experimentando possibilidades emergentes que são nossas de direito. Corpos-produto e produtores de cultura. Sendo assim, o nosso entendimento foi de que o corpo é linguagem e, como tal, nos permite simplesmente ser, ocupar espaços, fazer parte do mundo e, com ele, construir sentidos, nos comunicarmos, dialogarmos, interagirmos. Por isso, o conhecimento que construímos acerca de nosso corpo nos possibilita compreender nossa própria existência neste mundo.

Nesse sentido, concordamos com Alves (2004) quando a autora afirma que a compreensão do corpo como linguagem nos desafia a analisá-lo como texto, que se altera e se transforma com a História, porque cada texto corporal é fruto de um diálogo com outros textos, com outros tempos com o passado e sua memória e, também, com seu futuro, seus projetos e sonhos. Assim, o corpo visto como linguagem a ser lida e compreendida 
como produto da cultura requer nossa instrumentalização para analisar os discursos que ele constrói, reconstrói e expressa. Enfim, o corpo como linguagem, produto e produtor de cultura, nos permite afirmar que o contexto sócio-cultural define quem somos nós, como são nossos corpos.

Partindo deste pressuposto surgiu mais uma questão, qual seja o entendimento do corpo hegemônico na contemporaneidade e como ele tem se operacionalizado no nosso dia a dia. Segundo Gonçalves e Azevedo (2007), seria o conceito de um corpo frágil, com limitações e em busca constante de perfeição, visto como um elemento que impede e define os limites da pessoa, local onde começa e acaba a presença do indivíduo e que sofre influência inegável da sociedade - uma condição material da existência da vida no mundo. Esse entendimento de corpo, na contemporaneidade, implica uma valoraçấo da aparência desse corpo na sociedade ${ }^{2}$, e, conseqüentemente, de técnicas e recursos tecnológicos ${ }^{3}$ que propiciem o "alcance" de um determinado tipo de "corpo ideal".

Nesses casos, realizamos, com nossos alunos, uma mesa-redonda, na qual contamos com a participação de uma acadêmica da Faculdade de Educação Física da UFG e de um professor de Educação Física que estudavam, respectivamente, a utilização do Orkut (sítio virtual de relacionamento) como um recurso utilizado por escolares para alterarem suas aparências e a comercialização de práticas corporais em academias de ginástica da cidade de Goiânia.

2 A aparência corporal responde a uma ação do ator relacionada com o modo de se apresentar socialmente e de se representar quotidianamente. Engloba a maneira de se vestir, de se pentear e ajeitar o rosto, de cuidar do corpo, entre outras, que muda conforme as circunstâncias e de acordo com o estilo da presença do indivíduo (Gonçalves e Azevedo, 2007).

3 A crescente evolução e a utilização de novas tecnologias acarretam profundas mudanças nos modos de vida da populaçáo, colocando os indivíduos diante de desafios, cuja maioria não está preparada para enfrentar. Com a racionalidade crescente no século XIX, que atribuiu ao homem a tarefa de dominar/explorar a natureza, aliada ao também crescente processo de industrialização, o desenvolvimento centrado na ciência tecnológica é visto, portanto, como sinônimo de progresso. Assim, ressalta-se que moldamos nosso corpo com grande auxílio da tecnologia de modo a padronizá-lo, com maior incisão. Percebemos que o avanço tecnológico vai desde simples reparos, utilizando-se de maquiagens até tratamentos cirúrgicos, não acessíveis a todas as classes sociais, pois não seria a qualquer mortal insatisfeito que essas tecnologias estariam disponíveis para fazer um upgrade (Gonçalves e Azevedo, 2007). 
Além da utilização de estratégias como a realização de uma mesaredonda, leitura de textos e, na seqüência, debates sobre o que tem ocorrido no tocante à concepção de corpo nos dias atuais, discutimos com nossos alunos como este entendimento a respeito do corpo tem sido hegemônico em nossa sociedade, além do fato de como os discursos e as práticas corporais têm sido operacionalizados pela sociedade.

\section{SEQÜENCIAdor DE aUlas, UNIDAde DE aVANÇO PROGRAMÁTICO}

Apresentamos, a seguir, o seqüenciador de aulas e a unidade de avanço programático que fizeram parte da estratégia de ensino desenvolvida com os alunos do Ensino Médio.

Objetivo Geral: Compreender de forma crítica o Corpo, como Linguagem, bem como a sua utilização social e política nas relaçóes de poder historicamente construídas pelo Homem.

\begin{tabular}{|c|c|c|}
\hline $\begin{array}{c}\text { OBJETIVOS } \\
\text { ESPECÍFICOS }\end{array}$ & $\begin{array}{c}\text { CONTEÚDO } \\
\text { PROGRAMÁTICO }\end{array}$ & ATIVIDADES \\
\hline $\begin{array}{l}\text { Conceituar lin- } \\
\text { guagem verbal } \\
\text { e não-verbal; }\end{array}$ & $\begin{array}{l}\text { Unidade I - Os diferentes } \\
\text { tipos de linguagem } \\
\text { 1.1 Linguagem verbal e } \\
\text { não verbal. }\end{array}$ & $\begin{array}{l}\text { 1. Texto didático "Linguagem } \\
\text { Verbal e Não-Verbal” e slides } \\
\text { sobre o conteúdo. }\end{array}$ \\
\hline $\begin{array}{l}\text { Saber identifi- } \\
\text { car, por meio } \\
\text { de imagens e } \\
\text { das diferentes } \\
\text { manifestaçóes } \\
\text { do corpo, a } \\
\text { expressão deste } \\
\text { como lingua- } \\
\text { gem; }\end{array}$ & $\begin{array}{l}\text { Unidade II - Corpo e } \\
\text { linguagem } \\
2.1 \text { Corpo como uma das } \\
\text { manifestaçóes da linguagem; } \\
2.2 \text { O corpo como instru- } \\
\text { mento de comunicação } \\
\text { (imagens que ilustram e as } \\
\text { diferentes manifestaçôes do } \\
\text { corpo). }\end{array}$ & $\begin{array}{l}\text { 1. Vídeo de dança (Formação de } \\
\text { imagens a partir dos corpos } \\
\text { dos bailarinos); } \\
\text { 2. Atividade de mímica (Jogo } \\
\text { Imagem em Açáo) e de } \\
\text { imagens artísticas e peças de } \\
\text { museus; } \\
\text { 3. Discussáo sobre as atividades } \\
\text { realizadas, relacionando-as } \\
\text { com a discussão do texto } \\
\text { "Linguagem Verbal e Não- } \\
\text { Verbal"; } \\
\text { 4. Atividade "paródia - pará- } \\
\text { frase". }\end{array}$ \\
\hline
\end{tabular}


(continuação)

\begin{tabular}{|c|c|c|}
\hline $\begin{array}{c}\text { OBJETIVOS } \\
\text { ESPECÍFICOS }\end{array}$ & $\begin{array}{c}\text { CONTEÚDO } \\
\text { PROGRAMÁTICO }\end{array}$ & ATIVIDADES \\
\hline $\begin{array}{l}\text { Discutir o } \\
\text { corpo enquan- } \\
\text { to construção } \\
\text { cultural. }\end{array}$ & $\begin{array}{l}\text { Unidade III - O corpo e a } \\
\text { construçáo da cultura } \\
3.1 \text { A historicidade do corpo; } \\
\text { 3.2 O corpo e a construção } \\
\text { da identidade (individual e } \\
\text { sócio-cultural); } \\
\text { 3.3 Corpo e imagem: a } \\
\text { construção do olhar do outro } \\
\text { e a promoção de um estilo } \\
\text { corporal de vida. }\end{array}$ & $\begin{array}{l}\text { 1. Atividade: Você tem ou vocêé } \\
\text { um corpo? (roteiro de atividade } \\
\text { e apresentação de slides); } \\
\text { 2. Mesa-redonda: Bruno de } \\
\text { Oliveira e Silva - As três faces } \\
\text { de Eva nas academias de } \\
\text { Goiânia e Ana Carolina Jubé - } \\
\text { Representação e Virtualização do } \\
\text { Corpo de Escolares no Orkut; } \\
\text { 3. Texto didático "A construçáo } \\
\text { dos sentidos de corpo e } \\
\text { linguagem na sociedade } \\
\text { ocidental" - Vânia Alves - } \\
\text { Projeto Veredas/Minas Gerais/ } \\
\text { Unidade 1: Educação Corporal; } \\
\text { 4. Poema de Carlos Drummond } \\
\text { de Andrade - "Eu, Etiqueta" } \\
\text { Discussão sobre o Corpo } \\
\text { Mercadoria; } \\
\text { 5. Discussão sobre as atividades } \\
\text { realizadas e as palestras, } \\
\text { relacionando-as com a con- } \\
\text { cepção de corpo orientadora } \\
\text { do projeto de ensino; } \\
\text { 6. Texto didático "O estereótipo } \\
\text { de corpo/linguagem construí- } \\
\text { do na contemporaneidade" } \\
\text { - Andréia Santos Gonçalves } \\
\text { e Aldo Antônio de Azevedo, } \\
\text { Revista Pensar a Prática. }\end{array}$ \\
\hline $\begin{array}{l}\text { Analisar o uso } \\
\text { social e político } \\
\text { do corpo. }\end{array}$ & $\begin{array}{l}\text { Unidade IV - O uso social } \\
\text { e político do corpo } \\
\text { 3.1 Corpo e as relaçóes de } \\
\text { poder; } \\
\text { 3.2 Influência midiática no } \\
\text { processo de construção de } \\
\text { um conceito de corpo na } \\
\text { pós-modernidade. }\end{array}$ & $\begin{array}{l}\text { 1. Texto didático "Em busca da } \\
\text { gênese do uso social e político } \\
\text { do corpo" - Christiane Luce } \\
\text { Gomes Werneck; } \\
\text { 2. Texto didático "Corpo e } \\
\text { Poder" - Foucault, Microfísica } \\
\text { do Poder, capítulo IX. }\end{array}$ \\
\hline
\end{tabular}




\section{Revista Solta a Voz, v. 19, n. 2}

\section{CONSIDERAÇÓES FINAIS}

O trabalho interdisciplinar de Corpo e Linguagem constituiu-se como uma oportunidade para repensarmos a prática pedagógica em sala de aula. Os formatos tradicionais, embora importantes para a sistematização do conhecimento, podem compartilhar seu espaço com práticas experimentais, como citado acima. E o Cepae/UFG nos permite essa incursão, justamente porque se constitui como um campo de pesquisa educacional.

A existência de nosso curso foi possível porque houve um desejo de dois professores de desafiarem os limites do estudo conjunto, da apresentação de sugestóes, da alteração de seus padróes de pensamento e, principalmente, do compartilhamento de saberes característicos de suas áreas de conhecimento: Educação Física e Língua Portuguesa e Lingüística. Esse processo de partilha foi fundamental para que a disciplina se concretizasse e pudéssemos pensá-la não mais como atividade única de disciplinas, pois, na verdade, surgiu outro objeto de conhecimento, interdisciplinar.

Algumas das estratégias aqui descritas podem ilustrar o que foi possível construir. Muitos resultados nos parecem satisfatórios, quando detectamos depoimentos como "a maneira como a disciplina tem sido dada é inédita, para nós, pois são temas que a gente conhece, tem acesso, mas que nunca foram tratados por dois professores (de Português e Educação Física)". Outros comentários foram muito importantes para entendermos a recepção desse tipo de trabalho por nossos alunos:

[...] O corpo vem sendo construído em busca de algo perfeito; mas a lógica capitalista náo é "burra", pois nunca se chegará a um corpo perfeito, porque um novo produto "plus" é lançado no mercado, depois um "advanced" e tantas outras nomenclaturas de produtos que são a solução dos nossos problemas. (Aluno A)

ou

É que o conceito de corpo, nos dias atuais, é puramente capitalista e somos rodeados dessas ideologias. [...] O limite de nossa liberdade é limitado; a sociedade nos "engole" e não temos escolha a não ser definir em que academia ou qual produto de beleza vou consumir. (Aluno B) 
Além disso, propiciar temas mais complexos como Corpo e Mercadoria, Corpo, Linguagem e Poder constituiu um desafio para nossos alunos, já acostumados à reflexão de textos jornalísticos, teóricos, em certa medida, a pensarem sobre um objeto "novo" de estudo para eles, e, para nós, a temática abordada em nossa disciplina constituiu-se também um objeto de pesquisa, durante mais de um ano, desde a preparação teórico-metodológica do curso até sua execução.

Evidentemente, encontramos alguns problemas durante o percurso. Por exemplo, a organização pedagógica do Cepae, em subáreas, ainda ocorre de forma fragmentada, por isso, trabalho como o nosso, que iniciou um processo de desenvolvimento de uma experiência interdisciplinar, ainda não tem o respaldo necessário para que sua organização se efetive a contento. Trabalhos de natureza interdisciplinar ainda são a exceção e não a regra. Nesse sentido, acreditamos que se faz necessário repensarmos e reorganizarmos a articulação entre tempo, espaço e conhecimento nas instituições escolares.

Associa-se a isso mais dois elementos: o primeiro é a excessiva carga de trabalho que nós, professores de Educação Básica, sob regime de trabalho do Magistério Superior, temos que assumir, quais sejam: ensino, pesquisa e extensão, eixos que norteiam o trabalho acadêmico numa instituição educacional superior pública. Toda e qualquer ação pedagógica, interdisciplinar, está amparada pela idéia de que o espaço e o tempo de pesquisa e desenvolvimento de um projeto necessita de uma situação diferenciada, pois requer uma ou mais pessoas discutindo e reelaborando o conhecimento. Assim, aulas mais significativas, que exigem dos profissionais dedicação, ficam prejudicadas, o que, de forma geral, acaba impossibilitando um tempo maior para discussão e debate na elaboração e desenvolvimento de cursos interdisciplinares. Isso não se dá somente no âmbito de trabalhos (inter)disciplinares, mas em todo trabalho de pesquisa que envolva outros indivíduos, oriundos de outras áreas do conhecimento.

Outra dificuldade encontrada foi a busca de materiais didático-pedagógicos coerentes com os fundamentos teórico-metodológicos das duas áreas, Educação Física e Língua Portuguesa. Nesse sentido, acreditamos que as instituiçóes de Educação Básica, vinculadas às IFES, podem se efetivar como escolas de qualidade, com propostas pedagógicas inovadoras, atuando no processo de formação de professores, somente se não adotarem o modelo de "escola-massa", evidenciando uma atuação política junto aos 


\section{Revista Solta a Voz, v. 19, n. 2}

nossos representantes sindicais e políticos, de maneira a impedir o processo de precarização do trabalho docente, em voga nas IFES.

Propostas de trabalhos interdisciplinares surgem do desejo dos professores proporem outras abordagens de cunho teórico-metodológico para as situaçóes de ensino-aprendizagem, com o intuito de promover a formação universal do homem. Esses projetos têm como substrato a melhoria do ensino e da aprendizagem dos alunos, em qualquer nível. Todo trabalho de elaborar uma disciplina, pensar estratégias que podem ser direcionadas a uma única disciplina curricular toma uma dimensão maior na elaboração de um curso interdisciplinar. Todo trabalho de ensino pressupóe pesquisa.

A interdisciplinaridade surge como uma possibilidade de trabalho coletivo, cooperativo. Para ele se efetivar é necessário vontade, disposição; é necessário também desejar partilhar posições, ceder, retroceder, redimensionar o objeto de estudo. Portanto, é um trabalho de avaliação do próprio educador/pesquisador e não somente dos resultados obtidos pelos alunos. Os problemas enfrentados por nós na execução da disciplina Corpo e Linguagem não são problemas diferentes dos que enfrentamos nos cursos regulares, do Ensino Médio ou mesmo do Ensino Superior. É um problema da Educação atual que vem sendo fragmentada ou, como afirma Bourdieu (1982, p. 64),

todo sistema de ensino institucionalizado (SE) deve as características específicas de sua estrutura e de seu funcionamento ao fato de que lhe é preciso produzir e reproduzir, pelos meios próprios da instituiçáo, as condições institucionais cuja existência e persistência (auto-reprodução da instituição) são necessários tanto ao exercício de sua função própria de inculcação quanto à realização de sua função de reprodução de um arbitrário cultural do qual ele não é o produtor (reprodução cultural) e cuja reprodução contribui à reprodução das relaçóes entre os grupos ou as classes (reprodução social).

O trabalho interdisciplinar também é uma representação do mundo e da educaçáo moderna, evidenciando as lutas de poder que as envolve. No entanto, a escola, mesmo reproduzindo todo um sistema histórico, social e político, também é o lócus da reflexão crítica, de propostas desafiadoras do sistema atual. Segundo Barros (2007, p. 4), 
o campo (que não é uma estrutura fixa, mas a exteriorização do habitus em sociedade), enquanto lócus da disputa por poder, é o ambiente idealizado para a luta intelectual, econômica e entre os indivíduos e instituiçôes. Deste modo, numa sala de aula, o que se tem é o espaço para "lutas intelectuais" que, em si, representam uma construção social da realidade ou relaçôes objetivadas. O que se passa na sala de aula, entre professor e aluno, tende a estruturar o habitus de ambos os agentes envolvidos no processo de ensino e aprendizagem. Destarte, o campo é a personificação da subsistência da diferença, do conflito, da solidariedade e conivência, já que é o lócus do conjunto de relaçôes de força dos agentes e/ou instituiçóes, numa espécie de peleja por mais poder que, no caso dos PEs, recebe valor e preço, além de mercado específico.

Em nossa disciplina, a apresentação de uma temática diferenciada, trabalhada por professores de áreas distintas, permitiu não somente uma integração e interesse dos alunos, como nos permitiu rever nossas práticas educacionais e entender a necessidade de "criarmos" um objeto novo de estudo, já abordado pela Análise do Discurso, pela Sociologia e até mesmo pela Educação Física. A constituição de Corpo e Linguagem, como disciplina, foi desafiadora porque nos permitiu aproximar as linguagens e as condiçóes para transformarmos uma idéia possível num objeto de estudo e pesquisa.

\section{REFERÊNCIAS}

ALVES, V. de F. N. A construção dos sentidos de corpo na sociedade ocidental. Projeto Veredas-Unidade 1/Educação Corporal. p. 23-52. 2004.

ARANHA, L. Pedagogia histórico-crítica: o otimismo dialético em educação. São Paulo: Educ, 1992.

ASSIS, M. et al. O dito e o interdito: análise das formações discursivas produzidas pela mídia impressa acerca do papel atribuído à dança em projetos sociais na cidade do Rio de Janeiro. Ciências do Esporte, Campinas, São Paulo, v. 26, n. 2, p. 7-180, 2005.

BAKHTIN, M. Marxismo e filosofia da linguagem. São Paulo: Hucitec, 1997.

. Pensamento e linguagem. São Paulo: Martins Fontes, 1999. 
BARROS, S. M. Da reprodução cultural nos planos de ensino de Sociologia. Verinotio - Revista online de Educação e Ciências Humanas, n. 7, Ano IV, nov. 2007. Disponível em: <http://www.verinotio.org/revista7_reproducao.htm>. Acesso em: 05 mai. 2008.

BOURDIEU, P. A Reprodução: elementos para uma teoria do sistema de ensino. 2. ed. Rio de Janeiro: Livraria Francisco Alves Editora S.A, 1982.

; CHAMBOREDON, J.-C.; PASSERON, J.-C. A profissão de Sociólogo: preliminares epistemológicas. Rio de Janeiro: Vozes, 1999.

CENTRO DE ENSINO E PESQUISA APLICADA À EDUCAÇÃO DA UFG. Disponível em: <http://www.cepae.ufg.br>. Acesso em: 27 abr. 2006.

COLETIVO DE AUTORES. Metodologia do ensino de educação física. São Paulo: Cortez, 1992.

DELGADO, A. F. et al. A reforma Curricular do Ensino Médio no Cepae sob a perspectiva dos alunos. Revista Solta a Voz, Goiânia, n. 2, p. 135-156, jul./ dez. 2007.

FILHO, C. de B.; MARTINO, L. M. S. O habitus na comunicação. Paulus: São Paulo, 2003.

FOUCAULT, M. A microfisica do poder. Rio de Janeiro: Edições Graal, 1979.

FREITAS, L. C. de. Crítica da organização do trabalho pedagógico e da didática. Campinas: Papirus, 1995.

GONÇALVES, A. S.; AZEVEDO, A. A. A re-significação do corpo pela educação física escolar, face ao estereótipo construído na contemporaneidade. Revista Pensar a Prática, Goiânia, v. 10, n. 2, p. 201-219, jul./dez. 2007.

GRAMSCI, A. Concep̧̧ão dialética da história. Rio de Janeiro: Civilização Brasileira, 1987.

KOPNIN, P. V. A dialética como lógica e teoria do conhecimento. Rio de Janeiro: Civilização Brasileira, 1978.

LOPES, J. T. Razão, corpo e sentimento na teoria social contemporânea. Revista da Faculdade de Letras: Sociologia, série I, v. 9, p. 57-64, 1999. Disponível em: <www.ler.letras.up.pt/uploads/ficheiros/1490.pdf>. 
MUÑOZ PALAFOX, G. H. Intervenção e conhecimento: a importância do planejamento de currículo e da formação continuada para a transformação da prática pedagógica. 2001. 402f. Tese (Doutorado em Educação) - Pontifícia Universidade Católica de São Paulo, São Paulo, 2001.

NECKEL, N. Do discurso artístico à percepção de diferentes processos discursivos. Anais da ANPOLL, Pontifícia Universidade Católica de São Paulo: São Paulo, 2006.

PÊUCHEUX, M. Semântica e discurso: uma crítica à afirmação do óbvio. 3. ed. Campinas: Editora da Unicamp, 1997.

PINTO, J. P. Sobre discurso feminista em publicaçóes: a política do grupo Transas do Corpo. Revista Estudos Femininos, Universidade Federal do Rio de Janeiro, Rio de Janeiro, v. 12, número especial, p. 106-114, set./dez. 2004.

GOIÂNIA/CEPAE/UFG. Plano de Ensino da Subárea de Lingua Portuguesa. Goiânia: CEPAE, 20008.

PORTER, R. A história do corpo. In: BURKE, P. (Org.). A escrita da história: novas perspectivas. São Paulo: Ed. da Unesp, 1992. p. 291-326.

WERNECK, C. L. G. Educação Física: em busca da gênese do uso social e político do corpo. Mimeo, 2003.

Recebido em: 01 jun. 2008

Aceito em: 16 set. 2008 